\title{
Structural and electrical conductivity of CH:MC bio-poly-blend films: optimize the perfect composition of the blend system
}

\author{
OMED G H ABDULLAH ${ }^{1,2, *}$, RAWAD R HANNA ${ }^{3}$ and YAHYA A K SALMAN ${ }^{3}$ \\ ${ }^{1}$ Advanced Materials Research Lab., Department of Physics, College of Science, University of Sulaimani, \\ 46001 Sulaimani, Iraq \\ ${ }^{2}$ Komar Research Center, Komar University of Science and Technology, 46001 Sulaimani, Iraq \\ ${ }^{3}$ Department of Physics, College of Science, University of Mosul, 41002 Mosul, Iraq \\ *Author for correspondence (omed.abdullah@univsul.edu.iq)
}

MS received 24 May 2017; accepted 14 August 2018; published online 6 March 2019

\begin{abstract}
In this study, solid polymer blend films based on chitosan $(\mathrm{CH})$ and methylcellulose (MC) were prepared in various compositions by the solution cast technique. The features of structure and complexation of the blend polymer films were studied using X-ray diffraction (XRD) and Fourier transform infrared (FTIR) analysis. The shift of FTIR peaks of the amino groups of $\mathrm{CH}$ and the hydroxyl groups of $\mathrm{MC}$ reveals the formation of interchain hydrogen-bonding between $\mathrm{CH}$ and $\mathrm{MC}$ chains in blend films. From the XRD pattern, the semi-crystalline structure of $\mathrm{CH}$ was depressed with the addition of MC and shows the $\mathrm{CH}$ :MC blend system with ratio 75:25 has the minimum degree of crystallinity. The highest room temperature conductivity was found to be $0.05 \times 10^{-6} \mathrm{~S} \mathrm{~cm}^{-1}$ for $75 \mathrm{CH}: 25 \mathrm{MC}$ blend polymer composition. The dc conductivity exhibits Arrhenius-type behaviour with temperature. The drastic increase in conductivity up to $37.92 \times 10^{-6} \mathrm{~S} \mathrm{~cm}^{-1}$ at $373 \mathrm{~K}$, can be explained by free volume model. The highest value of electrical conductivity for all prepared samples was associated with the minimum value of activation energy.
\end{abstract}

Keywords. Polymer blend films; degree of crystallinity; electrical conductivity; activation energy.

\section{Introduction}

In the last few decades, much effort has been devoted to develop environmentally-friendly biodegradable polymer electrolytes based on natural polymers, such as chitosan $(\mathrm{CH})$, cellulose, starch and poly ( $\varepsilon$-caprolactone) (PCL) as host materials, instead of using not-eco-friendly and non-biodegradable synthetic polymers such as polyethylene oxide, polyvinyl chloride, polymethylmethacrylate, polyvinyl acetate (PVA), polyacrylonitrile and polyvinyl pyrrolidone (PVP) that impose several ecological issues [1-3].

It has been well reported in the literature that the ion transport in polymer electrolyte is predominant through amorphous phase rather than the crystalline phase [4]. Thus to modulate the conductivity of the polymeric system, many investigations have been focussed on increasing the amorphous phase of the polymer host material $[5,6]$. For this purpose, several methods and techniques were used such as copolymerization, blending and addition of salt, plasticization or ceramic nano-fillers [7-9]. Among these methods, polymer blending has received ever-increasing interest [10]. The polymer blends or polymer mixture often exhibit improved physical properties and better processing characteristics compared to the properties of pure polymer components [11]. The primary points of interest of the poly-blend systems are the simplicity of preparation, low basic cost and efficient control of physical properties via compositional change [10,12].
However, the manifestation of superior properties of blend polymers depends on the degree of miscibility of the components of blends on the molecular scale [13]. The basis of polymer-polymer miscibility may originate from any specific interaction, such as hydrogen-bonding, charge transfer complexes and dipole-dipole interactions $[14,15]$. In the present study, $\mathrm{CH}$ and methylcellulose (MC) have been chosen to prepare polymer-blend systems due to the excellent mechanical strength and good miscibility with each other [16]. Moreover, among all popular polymer electrolyte systems, a biopolymer electrolyte based on $\mathrm{CH}$ and $\mathrm{MC}$ has special significance in view of its potential applications in solid-state electrochemical devices, due to its many advantages such as water-soluble, biodegradable, biocompatible, non-toxic, environmentallyfriendly, abundant and good film-forming properties [17-19]. A literature search and intensive surveys reveal that a relatively small number of studies have been reported on the development of $\mathrm{CH}$ :MC blend-based polymer electrolyte systems [20].

Hamdan and Khiar [21] prepared a solid polymer electrolyte based on $\mathrm{CH}: \mathrm{MC}$ blends with an arbitrary fixed ratio of 50:50 complexed with different amounts of ammonium triflate $\left(\mathrm{NH}_{4} \mathrm{CF}_{3} \mathrm{SO}_{3}\right)$. Whereas, Misenan et al [22] have reported the effect of adding cellulose nanocrystal on the conductivity of $\mathrm{CH}: \mathrm{MC}$ blend in the ratio of 60:40. This report is concerned with the structural and electrical properties of $\mathrm{CH}$ and $\mathrm{MC}$ blends in different concentrations to find the optimal 
blend composition (the maximum amorphous domains). The electrical conductivity behaviour of the $\mathrm{CH}$ :MC poly-blend films are also reported.

\section{Experimental}

\subsection{Preparation of the polymer blend films}

In the present study, films of $\mathrm{CH}$ blended with $\mathrm{MC}$ were prepared using the solution cast technique at various weight ratios (100:0), (75:25), (50:50), (25:75) and (0:100). CH and MC were dissolved separately in $2 \%$ acetic acid and distilled water, respectively. The two solutions were stirred continuously for 2 days until the polymer powders were dissolved completely. After that, the two solutions were mixed according to desired weight ratio and the mixture was stirred at room temperature for $45 \mathrm{~min}$. Finally, the obtained homogeneous solutions were poured onto cleaned plastic Petri dishes and the solvent was allowed to evaporate slowly at ambient temperature to obtain free-standing films. The prepared films were then kept in desiccators with silica gel to eliminate all traces of the solvent.

\subsection{Characterization techniques}

Chemical modifications of the polymer due to blending were recorded using a Fourier transform infrared (FTIR) Spectrophotometer (Frontier spectrometer) in the wavelength range of $4000-400 \mathrm{~cm}^{-1}$. The X-ray diffraction (XRD) studies were conducted using (X'PERT-PRO) X-ray diffractometer with $\mathrm{CuK} \alpha$ radiation of wavelength $1.5406 \AA$ and a graphite monochromator, in the angle $10^{\circ} \leq 2 \theta \leq 70^{\circ}$ with a scan step size of $\Delta 2 \theta=0.1^{\circ}$. The electrical conductivity of the prepared films was measured using a Precision LCR Meter (Agilent/HP 4284A) in a frequency range of $100 \mathrm{~Hz}-1 \mathrm{MHz}$, and in the temperature range, 295-373 K. Here the polymer films were sandwiched between two aluminium electrodes under spring pressure (electrode-specimen contact area $=4.91 \mathrm{~cm}^{2}$ ) and the measurements were carried out in the conduction mode. The average thicknesses of these films were determined to be in the range 126-260 $\mu \mathrm{m}$. The real part of ac conductivity $\left(\sigma_{\mathrm{ac}}\right)$ was calculated from the measured values of conductivity $(G)$ using: $\sigma_{\mathrm{ac}}(\omega)=G d / A$, where $d$ is the thickness of the sample and $A$ is the electrodespecimen contact cross-sectional area.

\section{Results and discussion}

\subsection{FTIR studies}

Infrared spectral analysis monitors a wide variety of vibrational energy levels in the molecules [23]. The FTIR spectra of pure $\mathrm{CH}, \mathrm{MC}$ and their blends with different compositions recorded at room temperature are given in figure 1.
The FTIR spectrum of pure $\mathrm{CH}$ film shows a broad $\mathrm{O}-\mathrm{H}$ stretching absorption band between 3419 and $3289 \mathrm{~cm}^{-1}$, which is overlapped to the stretching vibration of $\mathrm{N}-\mathrm{H}$ in the same region. The $\mathrm{C}-\mathrm{H}$ stretching vibration bands occur between 2931 and $2925 \mathrm{~cm}^{-1}$. More major absorption bands at 1645 and $1564 \mathrm{~cm}^{-1}$ represent the $\mathrm{C}=\mathrm{O}$ stretching amino group I, and $-\mathrm{NH}$ bending amino group II of glucosamine, respectively [16]. The vibration modes at 1416, 1373 and $1152 \mathrm{~cm}^{-1}$ are respectively assigned to $\mathrm{CH}_{2}$ bending, $-\mathrm{CH}$ bending and anti-symmetric stretching of the $\mathrm{C}-\mathrm{O}-\mathrm{C}$ bridge [24].

From the FTIR spectrum of pure MC, it is observed that a strong broadband observed at $3459-3457 \mathrm{~cm}^{-1}$ is assigned to the stretching vibrations of hydroxyl groups $(\mathrm{O}-\mathrm{H})$. Moreover, the observed bands at 2934-2900 $\mathrm{cm}^{-1}$ indicate the presence of $\mathrm{C}-\mathrm{H}$ stretching of $\mathrm{CH}_{2}$ and $\mathrm{CH}_{3}$ groups. The observed strong band centred at $1647 \mathrm{~cm}^{-1}$ corresponds to $\mathrm{C}=\mathrm{O}$ stretching vibration and the observed band at $1412 \mathrm{~cm}^{-1}$ can be ascribed to the $\mathrm{C}-\mathrm{H}$ bending in $\mathrm{CH}_{2}$ [25,26], whereas the observed bands at $1374 \mathrm{~cm}^{-1}$ are assigned to $-\mathrm{CH}$ bending vibration. The band corresponding to the ether groups $(\mathrm{C}-\mathrm{O}-$ C) occurs at $1117 \mathrm{~cm}^{-1}$ [17], and the asymmetric vibrations of CO appear at $1087-1055 \mathrm{~cm}^{-1}$ [27].

The FTIR spectra of $\mathrm{CH}$ :MC blends shown in figure 1 contains no distinct additional absorbance peaks compared to those for pure $\mathrm{CH}$ and $\mathrm{MC}$. This suggests that there is no chemical interaction between the components [28], whereas the shift of some observed peaks suggests the physical interaction phenomena (i.e., ionic/hydrophobic interactions) between $\mathrm{CH}$ and $\mathrm{MC}$ chains. The shift in the position of the peak at $1564 \mathrm{~cm}^{-1}$ for $\mathrm{CH}$ amino groups (figure $1 \mathrm{~b}$ ) and peak at 3459-3457 $\mathrm{cm}^{-1}$ for MC hydroxyl groups (figure 1c), is due to hydrogen-bonding interaction between the positive charge of amino groups $\left(-\mathrm{NH}_{3}^{+}\right)$of $\mathrm{CH}$ and negative charge of hydroxyl groups $\left(-\mathrm{OH}^{-}\right)$of $\mathrm{MC}[29,30]$. Figure 2 shows the possible hydrogen-bonding between $\mathrm{CH}$ and $\mathrm{MC}$. The formation of a hydrogen bond between two polymers $\mathrm{CH}$ and MC upon blending proves miscibility between the two polymers at the molecular-level. Ragab [31] also attributed the miscibility between the two polymers PVA/PVP blend to the hydrogen-bonding between hydroxyl groups of PVA and carbonyl groups of PVP monomeric units.

\subsection{XRD studies}

The XRD is a versatile, non-destructive technique that reveals detailed information about the nature of polymer blend films and their crystallographic structure [32]. The XRD patterns of pure $\mathrm{CH}, \mathrm{MC}$ and their blend membranes were determined to correlate their structure with other properties. Figure 3 shows the diffractograms of $\mathrm{CH}, \mathrm{MC}$ and their blends. The pure polymers films show a peak around $2 \theta=21.1^{\circ}$ which usually characterizes the semi-crystalline phase of these polymers [33,34]. Previous studies addressed that intra- and inter-molecular hydrogen bonds are responsible for the semicrystalline structure of both $\mathrm{CH}$ and $\mathrm{MC}$ membranes [35,36]. 


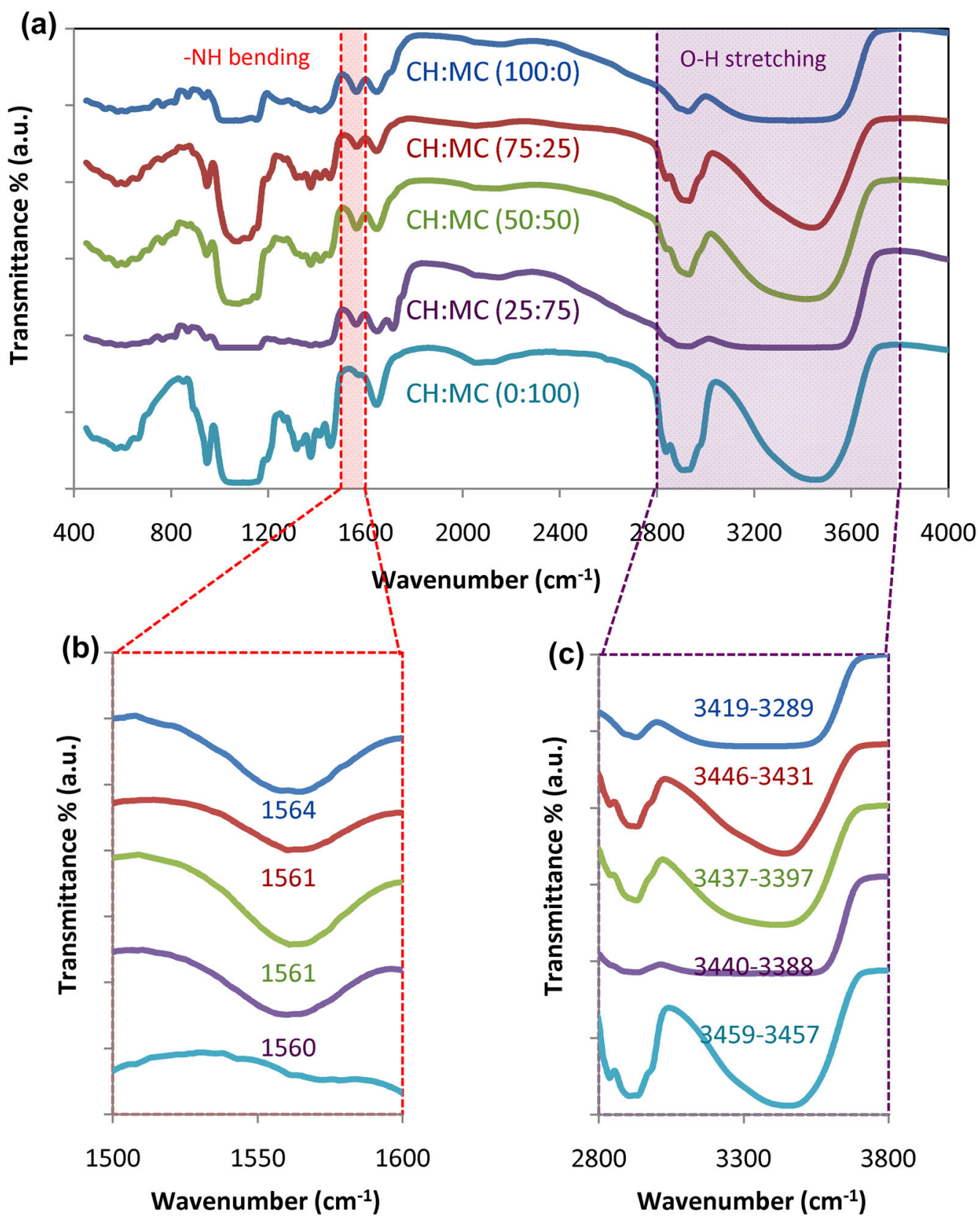

Figure 1. FTIR plots of $\mathrm{CH}: \mathrm{MC}$ polymer blend films at different weight ratios in the wavenumber ranges: (a) 400-4000 $\mathrm{cm}^{-1}$, (b) $1500-1600 \mathrm{~cm}^{-1}$ and (c) $2800-3800 \mathrm{~cm}^{-1}$.

The observed diffraction peak of $\mathrm{CH}: \mathrm{MC}$ blend films is less intense when compared with those of pure MC films, which indicates that the blending of $\mathrm{CH}$ and $\mathrm{MC}$ causes a reduction in the degree of crystallinity and a simultaneous increase in the amorphicity of the system. It was quoted in the literature that the crystallinity fractions are directly proportional to the peak intensity and inversely related to the full-width at halfmaximum of the peak $[37,38]$. The intensity of XRD peaks decreases as the amorphous nature increases $[39,40]$, and this amorphous nature facilitates the ionic diffusivity resulting in the increase of the electrical conductivity $[41,42]$, as it will be seen later on.
Resolution of crystalline peaks, together with an integration of the scattered intensities, provides a method for estimation of crystallinity. The degree of crystallinity $\left(X_{\mathrm{c}}\right)$ of the samples were determined by deconvoluting peaks due to crystalline and amorphous phases, using Fityk software [43], and according to Hermans and Weidinger equation $[44,45]$ :

$$
X_{\mathrm{c}}=\frac{A_{\mathrm{c}}}{A_{\mathrm{c}}+A_{\mathrm{a}}} \times 100 \%,
$$

where $A_{\mathrm{c}}$ and $A_{\mathrm{a}}$ are the area under crystalline peaks and amorphous haloes, respectively. The calculated data of degree 


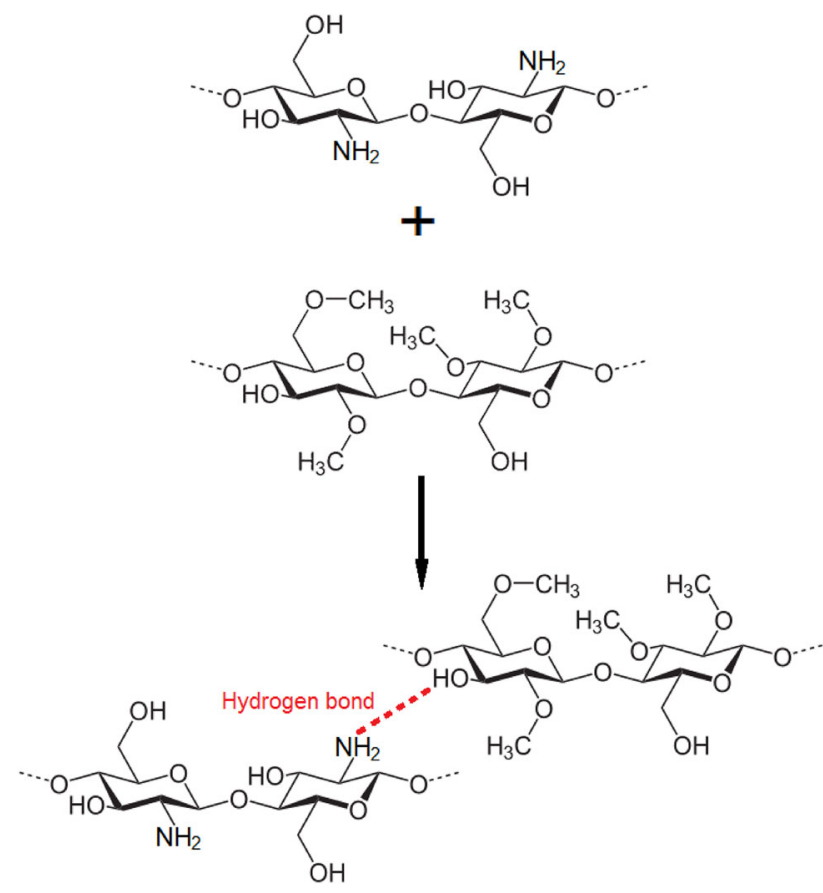

Figure 2. Possible mechanism for hydrogen-bonding between $\mathrm{CH}\left\{\mathrm{C}_{6} \mathrm{H}_{11} \mathrm{NO}_{4}\right\}_{n}$ and $\mathrm{MC}\left\{\mathrm{C}_{6} \mathrm{H}_{7} \mathrm{O}_{2}(\mathrm{OH}) x\left(\mathrm{OCH}_{3}\right) y\right\}_{n}$.

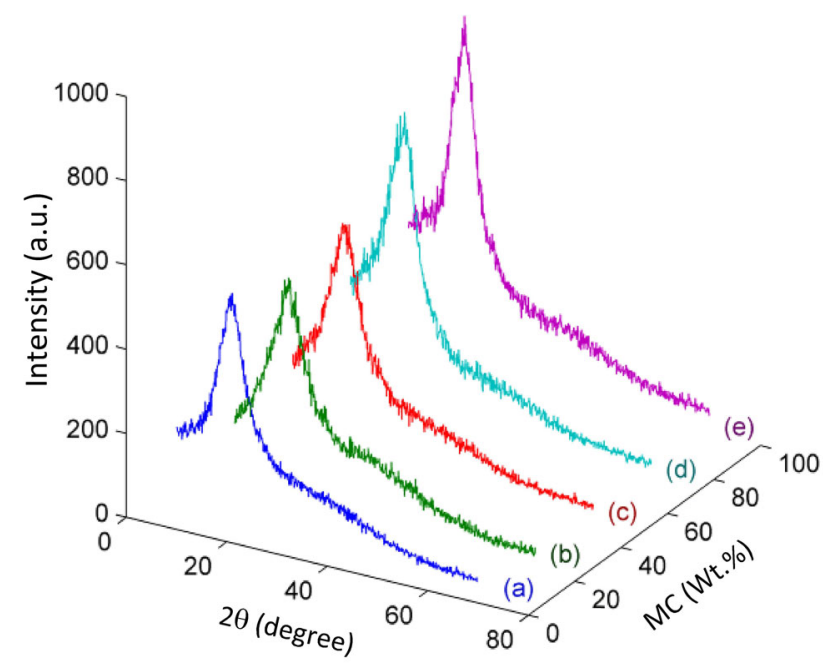

Figure 3. XRD patterns of $\mathrm{CH}: \mathrm{MC}$ polymer blend films at different weight ratios: (a) 100:0, (b) 75:25, (c) 50:50, (d) 25:75 and (e) 0:100.

of crystallinity for $\mathrm{CH}$ and $\mathrm{MC}$ blend samples of different compositions are shown in figure 4 . It is observed that the degree of crystallinity for blend samples lies in between the values of two pure polymers, which may be assigned to the incorporation of side branches [46]. As can be seen from figure 4 , the degree of crystallinity of the $75 \mathrm{CH}: 25 \mathrm{MC}$ polymer blend system is the lowest with a value of $(20.46 \%)$, suggesting that this composition has the maximum

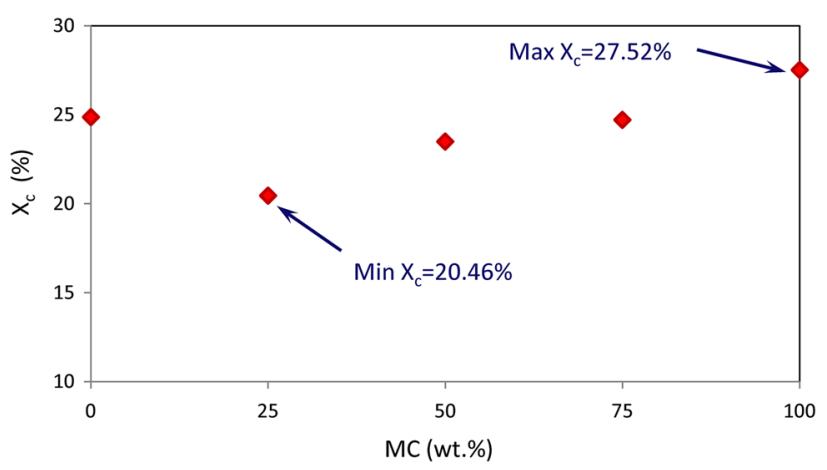

Figure 4. Degree of crystallinity of $\mathrm{CH}: \mathrm{MC}$ polymer blend films vs. MC wt $\%$.
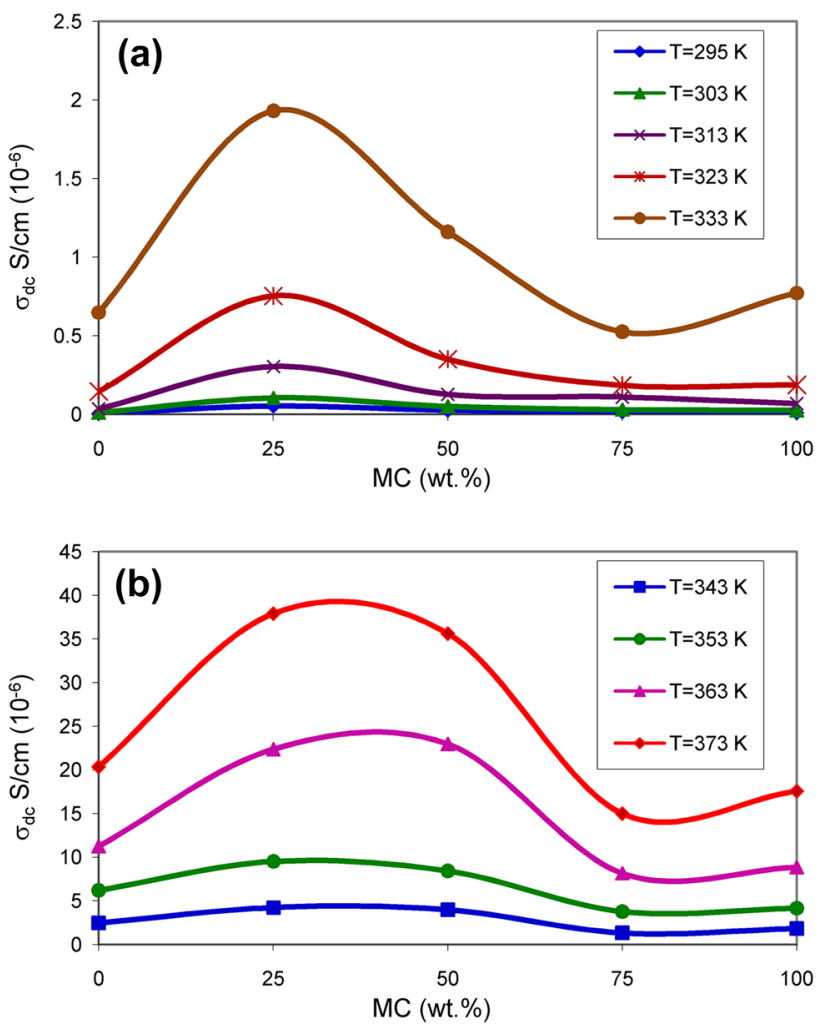

Figure 5. The variation of electrical conductivity vs. MC concentration at different temperature range: (a) 295-333 K and (b) $343-373 \mathrm{~K}$.

amorphicity. The increase in the amorphous nature causes a reduction in the energy barrier to the segmental motion of the polymer blend resulting in the increase in conductivity [47].

\subsection{Electrical conductivity studies}

The electrical conductivity of $\mathrm{CH}: \mathrm{MC}$ bio-polymer blend has been investigated, with an aim to understand the origin 
and nature of the charge transport prevalent in this material system. The low-frequency plateau region of electrical conductivity describes the electrode-specimen interface phenomena is attributed to the space charge polarization at the blocking electrode and is associated with the dc conductivity $\left(\sigma_{\mathrm{dc}}\right)$ of the polymer system [48]. Thus the frequency dependent electrical conductivity measurements can be used to obtain the dc conductivity $\left(\sigma_{\mathrm{dc}}\right)$ of the polymer blend region on the electrical conductivity axis to zero frequency (not shown here). The variation of the dc conductivity $\left(\sigma_{\mathrm{dc}}\right)$ vs. MC concentration at different temperatures is shown in figure 5. The obtained conductivity values for pure $\mathrm{CH}$ $\left(1.2 \times 10^{-8} \mathrm{~S} \mathrm{~cm}^{-1}\right)$, and pure MC $\left(2.6 \times 10^{-8} \mathrm{~S} \mathrm{~cm}^{-1}\right)$ are respectively in accordance with the results reported by $\mathrm{Ng}$ and
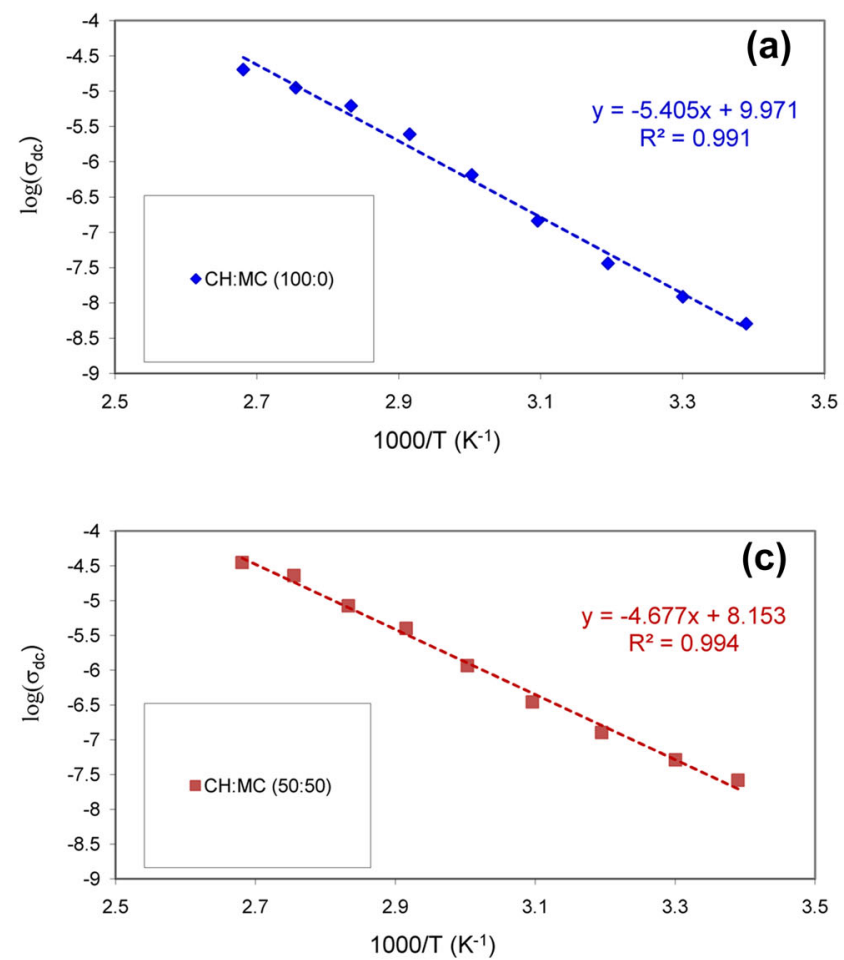
films at different temperatures by extrapolating the plateau

Mohamad [49] for $\mathrm{CH}$, and the results reported by Shuhaimi et al [50] for MC. The maximum conductivity of $\mathrm{CH}: \mathrm{MC}$ bio-poly blends was obtained for a composition ratio 75:25, which is ascribed to the increase in the amorphous nature of the polymer blend at this concentration, which is well consistent with the XRD results. Also, it is evident that the electrical conductivity of polymer blend systems increases with increasing temperature. The value of dc conductivity for the $75 \mathrm{CH}: 25 \mathrm{MC}$ membrane was found to increase with increasing temperature from $0.05 \times 10^{-6} \mathrm{~S} \mathrm{~cm}^{-1}$ at ambient temperature, to $37.92 \times 10^{-6} \mathrm{~S} \mathrm{~cm}^{-1}$ at $373 \mathrm{~K}$. The significant increase in dc conductivity with temperature can be explained by means of the free-volume model. According to this model, the increase in temperature results in an increase in the fraction of free volume [51]. This will facilitate the
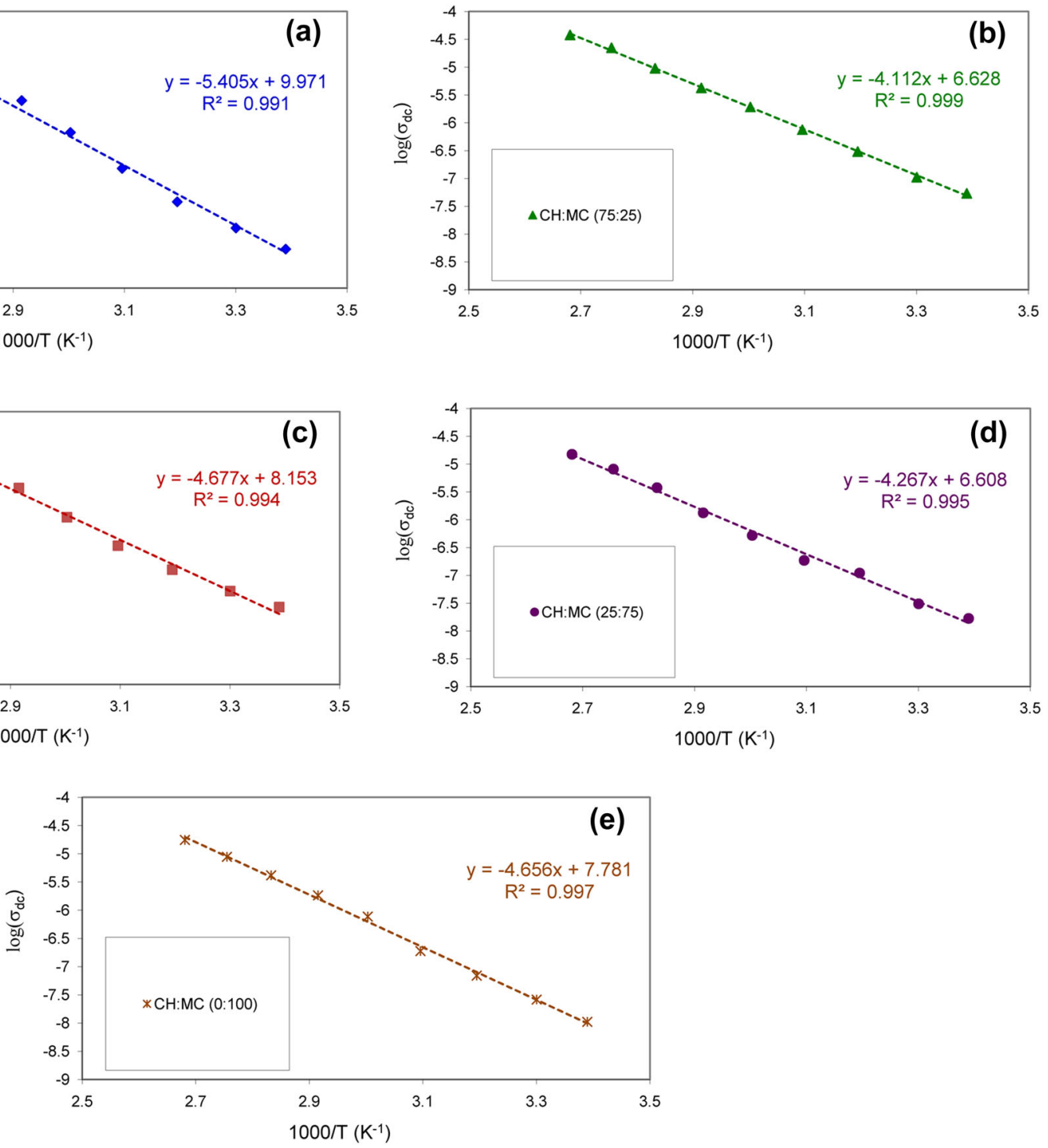

Figure 6. Temperature dependence dc conductivity of $\mathrm{CH}: \mathrm{MC}$ polymer blend films at different weight ratios: (a) 100:0, (b) 75:25, (c) 50:50, (d) 25:75 and (e) 0:100. 
segmental motion of polymer chains, which helps the migration of charge carriers by hopping from one site to another and sequentially increase the electrical conductivity [52,53].

The temperature dependence dc conductivity followed an Arrhenius behaviour in the studied temperature range. The dc conductivity $\left(\sigma_{\mathrm{dc}}\right)$ as per Arrhenius relation can be expressed as [54]:

$$
\sigma_{\mathrm{dc}}=\sigma_{0} \exp \left(-E_{\mathrm{a}} / k_{\mathrm{B}} T\right)
$$

where $\sigma_{0}$ is a proportionality constant related to the number of charge carriers in the films, $E_{\mathrm{a}}$ is the activation energy, $k_{\mathrm{B}}$ is the Boltzmann constant and $T$ is the temperature in Kelvin [55].

The activation energy (combination of defect formation energy and ion migration energy) corresponds to the energy required for conduction from one site to another [56-58]. For calculating $E_{\mathrm{a}}$ for dc conductivity, the effect of temperature on the $\sigma_{\mathrm{dc}}$ was studied. Figure 6 elucidates the linear dependence of logarithm of dc conductivity with inverse absolute temperature for $\mathrm{CH}: \mathrm{MC}$ poly-blend films. The regression values $\left(R^{2}\right)$ of the plots using linear fit have been found to be close to unity suggesting that the temperature dependent $\mathrm{dc}$ conductivity for all prepared films obey Arrhenius relationship. The activation energies were evaluated for individual pure polymers and their blend by considering the slope after linear fitting the data, using the relation [59]:

$$
E_{\mathrm{a}}=2.303\left(\frac{\log \sigma_{\mathrm{dc}}}{1 / T}\right) \frac{k_{\mathrm{B}}}{e} .
$$

The variation of activation energy $\left(E_{\mathrm{a}}\right)$ and room temperature dc conductivity $\left(\sigma_{\mathrm{dc}}\right)$ as a function of MC concentration is shown in figure 7. It is clear that the minimum value of $E_{\mathrm{a}}$ (in the order of $0.81 \mathrm{eV}$ for $75 \mathrm{CH}: 25 \mathrm{MC}$ poly-blend sample) is associated with the highest dc conductivity. The decrease in activation energy for polymer blend samples is attributed to

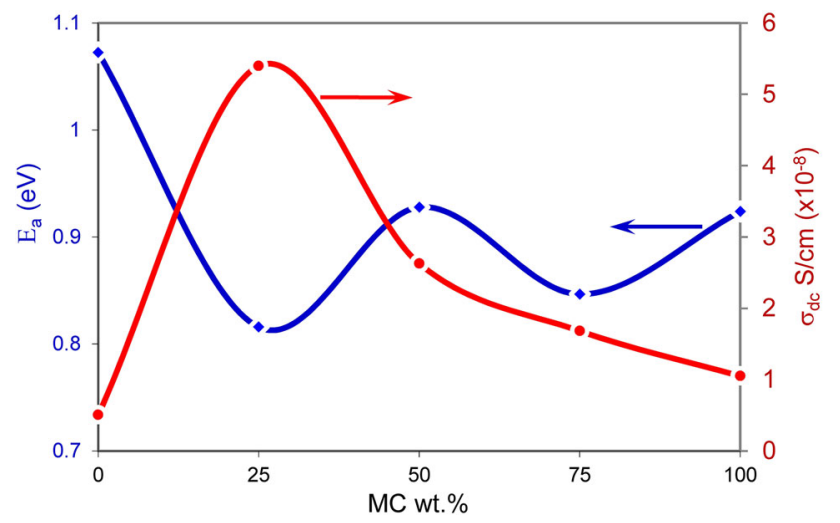

Figure 7. The variation of dc conductivity and activation energy as a function of $\mathrm{MC}$ wt $\%$ concentration. the reduction of the energy barrier to the segmental motion of polymer matrix. It is worth mentioning that the polymer electrolyte with a low value of activation energy is desirable for practical applications [60]. The inverse relationship between conductivity and activation energy was also reported earlier by Yousf et al [61] for starch-CH blend biopolymer films, and by Hafiza et al [62] for carboxyl $\mathrm{MC}-\mathrm{CH}$ blend polymer electrolyte.

Generally, the electrical conductivity is controlled by the concentration of mobile charge carriers and its mobility. In the present system, the increase in conductivity with increasing temperature should be mainly ascribed to the increase in the carrier mobility, due to the increment in the amorphous nature of the blend system (as confirmed by XRD analysis), which arises from the coordination and interaction between the amino groups of $\mathrm{CH}$ with hydroxyl groups of $\mathrm{MC}$ (as proved by FTIR analysis).

\section{Conclusions}

The perfect composition of MC:CH bio-poly-blend system for electrical conductivity was depicted using FTIR and XRD. The FTIR study indicates that $\mathrm{CH}$ can be effectively blended with $\mathrm{MC}$ due to the formation of hydrogen bond between functional groups of two polymers. The XRD pattern of blend samples reveal that the semi-crystalline structure of both $\mathrm{CH}$ and $\mathrm{MC}$ is reduced upon blending and the poly-blend samples with compositions of $75 \mathrm{CH}: 25 \mathrm{MC}$ showed the maximum amorphous content. The dc conductivity of this membrane increased with increase in sample temperature and followed Arrhenius equation. The highest electrical conductivity at $395 \mathrm{~K}$ has been found to be $0.05 \times 10^{-6} \mathrm{~S} \mathrm{~cm}^{-1}$ for the $75 \mathrm{CH}$ :25MC sample; the activation energy was found to be inversely proportional to the dc conductivity and was in the range $0.81-1.07 \mathrm{eV}$.

\section{Acknowledgements}

The authors would like to thank the Ministry of Higher Education and Scientific Research, University of Sulaimani, and Komar University of Science and Technology, for the financial support of this work.

\section{References}

[1] Muchakayala R, Song S, Gao S, Wang X and Fan Y 2017 Polym. Test. $\mathbf{5 8} 116$

[2] Kulshrestha N and Gupta P N 2016 Ionics 22671

[3] Khiar A S A and Arof A K 2010 Ionics 16123

[4] Aziz S B, Abdullah O G and Hussein S A 2018 J. Electron. Mater. 473800

[5] Aziz S B, Abdullah O G, Saber D R, Rasheed M A and Ahmed H M 2017 Int. J. Electrochem. Sci. 12363

[6] Abdullah O G 2016 J. Mater. Sci. Mater. Electron. 2712106 
[7] Abdulwahid R T, Abdullah O G, Aziz S B, Hussein S A, Muhammad F F and Yahya M Y 2016 J. Mater. Sci. Mater. Electron. 2712112

[8] Abdullah O G, Aziz S B and Rasheed M A 2017 J. Mater. Sci. Mater. Electron. 284513

[9] Aziz S B, Abdullah O G and Rasheed M A 2017 J. Appl. Polym. Sci. 13444847

[10] Abdullah O G, Aziz S B and Rasheed M A 2018 Ionics 24777

[11] Ramamohan K, Achari V B S, Sharma A K and Xiuyang L 2015 Ionics 211333

[12] Kesavan K, Mathew C M, Rajendran S, Subbu C and Ulaganathan M 2015 Braz. J. Phys. 4519

[13] Reddeppa N, Reddy T J R, Achari V B S, Rao V V R N and Sharma A K 2009 Ionics $\mathbf{1 5} 255$

[14] Lewandowska K 2009 Thermochim. Acta 49342

[15] Marsano E, Vicini S, Skopinska J, Wisniewski M and Sionkowska A 2004 Macromol. Symp. 218251

[16] Liu P, Wei X and Liu Z 2013 Adv. Mater. Res. 750-752 802

[17] Aziz N A N, Idris N K and Isa M I N 2010 Int. J. Polym. Anal. Charact. 15319

[18] Gomes A M M, Silva P L, Moura C L, Silva C E M and Ricardo N M P S 2011 . Macromol. Symp. 299/300 220

[19] Basavaraju K C, Damappa T and Rai S K 2006 Carbohyd. Polym. 66357

[20] Synytsya A, Grafova M, Slepicka P, Gedeon O and Synytsya A 2012 Biomacromolecules 13489

[21] Hamdan K Z and Khiar A S A 2014 Key Eng. Mater. 594-595 818

[22] Misenan M S M, Ali E S and Khiar A S A 2018 AIP Conf. Proc. 1972030010

[23] Praveena S D, Ravindrachary V, Bhajantri R F and Ismayi 2014 Polym. Composit. 27987

[24] Silva S S, Goodfellow B J, Benesch J, Rocha J, Mano J F and Reis R L 2007 Carbohyd. Polym. 7025

[25] Rangelova N, Radev L, Nenkova S, Salvado I M M, Fernandes M H V and Herzog M 2011 Cent. Eur. J. Chem. 9112

[26] Filho G R, Assuncao R M N, Vieira J G, Meireles C S, Cerqueira D A, Barud H S et al 2007 Polym. Degrad. Stabil. 92205

[27] Ragab H S and El-Kader M F H A 2013 Phys. Scr. 87025602

[28] Tang Y, Wang X, Li Y, Lei M, Du Y, Kennedy J F et al 2010 Carbohyd. Polym. 82833

[29] Hema M, Selvasekarapandian S, Arunkumar D, Sakunthala A and Nithya H 2009 J. Non-Cryst. Solids 35584

[30] Abdullah O G, Aziz S B and Rasheed M A 2016 Results Phys. 61103

[31] Ragab H M 2011 Physica B 4063759

[32] Rajeswari N, Selvasekarapandian S, Karthikeyan S, Prabu M, Hirankumar G, Nithya H et al 2011 J. Non-Cryst. Solids 357 3751

[33] Abdullah O G, Salman Y A K and Saleem S A 2016 J. Mater. Sci. Mater. Electron. 273591

[34] Abdullah O G and Saleem S A 2016 J. Electron. Mater. 45 5910
[35] Aziz S B, Abdulwahid R T, Rasheed M A, Abdullah O G and Ahmed H M 2017 Polymers 9486

[36] Aziz S B, Abdullah O G, Hussein S A and Ahmed H M 2017 Polymers 9622

[37] Wang J, Song S, Muchakayala R, Hu X and Liu R 2017 Ionics 231759

[38] Aziz S B, Abdullah O G and Rasheed M A 2017 J. Mater. Sci. Mater. Electron. 2812873

[39] Bdewi S F, Abdullah O G, Aziz B K and Mutar A A R 2016 J. Inorg. Organomet. Polym. Mater. 26326

[40] Abdullah O G, Tahir D A and Kadir K 2015 J. Mater. Sci. Mater. Electron. 266939

[41] Achari V B, Reddy T J R, Sharma A K and Rao V V R N 2007 Ionics 13349

[42] Abdullah O G, Aziz S B, Saber D R, Abdullah R M, Hanna R R and Saeed S R 2017 J. Mater. Sci. Mater. Electron. 28 8928

[43] Wojdyr M 2010 J. Appl. Crystallogr. 431126

[44] Sownthari K and Suthanthiraraj S A 2013 Express Polym. Lett. 7495

[45] Rani N S, Sannappa J, Demappa T and Mahadevaiah 2015 Ionics 21133

[46] El-Kader M F H and Ragab H S 2013 Ionics 19361

[47] Baskaran R, Selvasekarapandian S, Kuwata N, Kawamura J and Hattori T 2006 Solid State Ion. 1772679

[48] Abazine K, Anakiou H, El Hasnaoui M, Graca M P F, Fonseca M A, Costa L C et al 2016 J. Compos. Mater. 503283

[49] Ng L S and Mohamad A A 2008 J. Membrane Sci. 325 653

[50] Shuhaimi N E A, Teo L P, Woo H J, Majid S R and Arof A K 2012 Polym. Bull. 69807

[51] Elashmawi I S, Elsayed N H and Altalhi F A 2014 J. Alloy. Compd. 617877

[52] Dam T, Karan N K, Thomas R, Pradhan D K and Katiyar R S 2015 Ionics 21401

[53] Aziz S B, Rasheed M A, Saeed S R and Abdullah O G 2017 Int. J. Electrochem. Sci. 123263

[54] Hebbar V, Bhajantri R F and Naik J 2017 J. Mater. Sci. Mater. Electron. 285827

[55] Shukur M F, Ithnin R, Illias H A and Kadir M F Z 2013 Opt. Mater. 351834

[56] Mohan V M, Raja V, Bhargav P B, Sharma A K and Rao V V R N 2007 J. Polym. Res. 14283

[57] Badr S, Sheha E, Bayomi R M and El-Shaarawy M G 2010 Ionics 16269

[58] Raja V, Mohan V M, Sharma A K and Rao V V R N 2009 Ionics 15519

[59] Sugumaran S and Bellan C S 2014 Optik 1255128

[60] Ravi M, Bhavani S, Kumar K K and Rao V V R N 2013 Solid State Sci. 1985

[61] Yusof Y M, Shukur M F, Illias H A and Kadir M F Z 2014 Phys. Scr. 89035701

[62] Hafiza M N, Bashirah A N A, Bakar N Y and Isa M I N 2014 Int. J. Polym. Anal. Charact. 19151 